\title{
Age-Related Differences in Body Composition in Egyptian Obese Females
}

\author{
Moushira Zaki ${ }^{1}$, Sanaa Kamal ${ }^{1}$, Hala El-Bassyouni², Shams Kholoussi ${ }^{3}$, and Mona El-Gammal ${ }^{2}$ \\ ${ }^{1}$ Biological Anthropology Department, Medical Research Division, National Research Centre, Giza, Cairo 12311, Egypt; ${ }^{2}$ Clinical Genetics \\ Department, National Research Centre, Giza, Cairo 12311, Egypt; ${ }^{3}$ Immunogenetics Department, National Research Centre, Giza, Cairo \\ 12311, Egypt
}

Citation: Zaki M, Kamal S, El-Bassyouni H, Kholoussi S, El-Gammal M. Age-Related Differences in Body Composition in Egyptian Obese Females. Maced J Med Sci. 2013 Mar 15; 5773.2012 .0252$.

Key words: body composition; fat mass; anthropometry; aging.

Correspondence: Prof. Moushira Erfan Zaki, Biological Anthropology Department, Medical Research Division, National Research Centre Etmail: moushiraz@yahoo.com

Received: 03-Jun-2012; Revised: 10-Jul-2012; Accepted: 10-Aug-2012; Online first: 21-Nov-2012

Copyright: (๑) 2012 Zaki M. This is an openaccess article distributed under the terms of the Creative Commons Attribution License, which permits unrestricted use, distribution, and reproduction in any medium, provided the origin author and source are credited.

Competing Interests: The author have declared that no competing interests exist.

\section{Abstract}

Background: Body composition changes with age are of interest. They related to various health problems, excess accumulation of fat increases the risk of diseases such as diabetes mellitus, hypertension, osteoarthritis, and cardiovascular disease.

Objective: The aim of this study was to determine age differences in body composition among Egyptian obese females.

Design: A cross-sectional study was conducted in 600 obese females, 300 young (median age=19 yr) and 300 older (median age=40 yr). Body weight, height, waist and hip circumferences and body composition were measured.

Results: Older obese females had a significantly higher values of waist to hip ratio, fat mass (FM) and body fat mass percentage (FM\%) than younger obese females. On the other hand, they had a significantly lower values of fat free mass (FFM) and basal metabolic rate (BMR) as compared to younger females.

Conclusions: The study showed that proportion of fat mass is different between young and older obese females, although they had similar BMI. The greater decrease in FFM in older obese females might suggest loss of skeletal muscle mass.

\section{Introduction}

Body composition is considered to be related to various health problems. For example, obesity, excess accumulation of fat, increases the risk of all-cause mortality and diseases such as diabetes mellitus, hypertension and osteoarthritis. High BMI, increased waist circumference and therefore high fat mass have been associated with increased risk for cardiovascular disease and mortality [1-3].

The prevalence of obesity is steadily increasing in most countries with a Westernized lifestyle. Body composition is considered to be related to various health problems. It is well established that fat-free mass (FFM) decreases and fat mass (FM) increases with age [4]. Because the distribution of FFM and FM in different parts of the body may change with age, it is of interest to determine whether the distributions of lean and fat mass change with age and whether changes in the distribution of lean and fat mass are related to the decrease in BMR. The bioelectrical impedance analysis (BIA) is a noninvasive, easily applicable, inexpensive and practical 
method to assess body composition in population studies.

Excess accumulation of fat, increase the risk of all-cause mortality and diseases. Changes in body composition during the aging process result from decreases in total body water, bone mass and muscle mass, accompanied by an increase in body adiposity $[5,6]$. Young and old subjects of similar body size differ greatly in the body composition components [7]. Because weight and body mass index (BMI) alone are not adequate guides of underlying changes in FFM and fat mass during aging body composition analysis has been used in the clinical management programs of elderly women. NHANES III reported an effect of age and ethnicity on FFM [8]. The relationship between body fat and BMI in Hispanic-American women was different from that of European-American and African-American women where Hispanic-Americans had a greater total body fat for the same BMI [9]. Almost one third of the women in the Egyptian are classified as obese [10]. Although, the age-related changes in body composition is well described in American and European women [11], there is no study reported age-related.

There is no study reported age-related difference between young and older women in Egypt. Thus, the aim of this study is to determine age differences in body composition among healthy obese females.

\section{Subjects and Methods}

The study is based on 600 non-smoking healthy Egyptian females. The study included two groups of subjects. The first group was young females, aged between 15 and 25 years (median age = $19 \mathrm{yr}$ ) and the second group was older sedentary women, ages between 35 and 55 years (median age $=40 \mathrm{yr}$ ). Body weight, height waist and hip circumferences were measured according to the International Biological Programmer (IBP) [12]. Three measurements were obtained and the mean was considered for analysis. Body mass index (BMI) was calculated as the weight in kilograms divided by the square of the height in meters.

$\mathrm{BMI}$ of young women ranged between 30 and $32 \mathrm{~kg} / \mathrm{m}^{2}$ and between 31 and $33 \mathrm{~kg} / \mathrm{m}^{2}$ in older women. All subjects signed an informed consent statement. The Ethics Committee of National Research Centre approved the study protocol.

Subjects were collected between 2010 and 2012 , voluntarily attended the National Research Centre Clinics.
Subjects were excluded from analyses when the medical history indicated the presence of diseases.

Body composition was measured using bioelectrical impedance analysis (BIA) with TANITA SC - 330. The same investigators performed all the anthropometric and bioelectric impedance measurements to minimize inter investigators variability. The statistical analyses were performed, using the SPSS/ PC Statistical Package version 16.0 (SPSS Inc, Chicago, USA). Values presented as mean and standard deviation (S.D.). Differences in anthropometric data, body composition, between the two age groups were examined by using Student's unpaired t-test. Stepwise multiple linear regression analysis with BMR as the dependent variable and FFM, FM and age as independent variables was applied.

\section{Results}

Table 1 shows anthropometry and body composition for obese young and older women, expressed in means and SDs for all variables. Older subjects had a significantly higher WHR, fat mass and fat $\%$ than younger females. On the other hand, fat free mass and BMR were significantly higher in younger subjects compared to older women.

Table 1: Anthropometry and body composition in obese females.

\begin{tabular}{llc}
\hline Variable & Group & Mean \pm S.D. \\
\hline Age (year) & $15-25$ y & $20.75 \pm 4.99^{* *}$ \\
& $35-55$ y & $44.44 \pm 5.29$ \\
Weight $(\mathrm{kg})$ & $15-25 \mathrm{y}$ & $73.41 \pm 5.32^{* *}$ \\
& $35-55 \mathrm{y}$ & $83.55 \pm 6.05$ \\
BMI $\left(\mathrm{kg} / \mathrm{m}^{2}\right)$ & $15-25 \mathrm{y}$ & $31.85 \pm 4.14$ \\
& $35-55 \mathrm{y}$ & $32.51 \pm 4.22$ \\
Waist to hip ratio & $15-25 \mathrm{y}$ & $0.838 \pm 0.113^{\star *}$ \\
& $35-55 \mathrm{y}$ & $0.88 \pm 0.078$ \\
FFM $(\mathrm{kg})$ & $15-25 \mathrm{y}$ & $45.58 \pm 6.54^{* *}$ \\
& $35-55 \mathrm{y}$ & $35.749 \pm 7.59$ \\
FM $(\mathrm{kg})$ & $15-25 \mathrm{y}$ & $20.83 \pm 9.36^{* *}$ \\
& $35-55 \mathrm{y}$ & $34.80 \pm 8.24$ \\
Fat $\%$ & $15-25 \mathrm{y}$ & $30.68 \pm 8.946$ \\
& $35-55 \mathrm{y}$ & $41.49 \pm 6.217$ \\
BMR $(\mathrm{kJ} / \mathrm{d})$ & $15-25 \mathrm{y}$ & $6368.37 \pm 633.721^{* *}$ \\
**, P<0.001 - Significant difference between younger and older subjects.
\end{tabular}

Table 2 shows the relations between BMR, age and body composition. Our findings indicate that a greater proportion of the variability in BMR was explained by the regression model 3 that included lean, fat and age variables followed by model 2 that included lean and fat variables and then model 1 included lean mass variable only. 
Table 2: Multiple regression of BMR against age and body composition.

\begin{tabular}{cccccc}
\hline Model & Intercept & R2 & Slope & Beta & P \\
\hline $\begin{array}{c}\text { Model 1 } \\
\text { Constant }\end{array}$ & 4862.194 & 0.64 & - & - & $<0.001$ \\
Fat Free Mass & - & - & 44.385 & 0.799 & $<0.001$ \\
& & & & & \\
\hline Model 2 & & & & & \\
Constant & 3057.669 & 0.86 & - & - & $<0.001$ \\
Fat Free Mass & - & - & 34.535 & 0.622 & $<0.001$ \\
Free Mass & - & - & 43.646 & 0.502 & $<0.001$ \\
\hline Model 3 & & & & & \\
Constant & 3794.175 & 0.99 & - & - & $<0.001$ \\
Fat Free Mass & - & - & 39.054 & 0.703 & $<0.001$ \\
Fat Mass & - & - & 44.419 & 0.611 & $<0.001$ \\
Age & - & - & -20.551 & -0.377 & $<0.001$ \\
\hline
\end{tabular}

Figures 1 shows a positive correlations between age and FM\%. There was a significant trend showing higher values for fat mass percentage with advancing age.

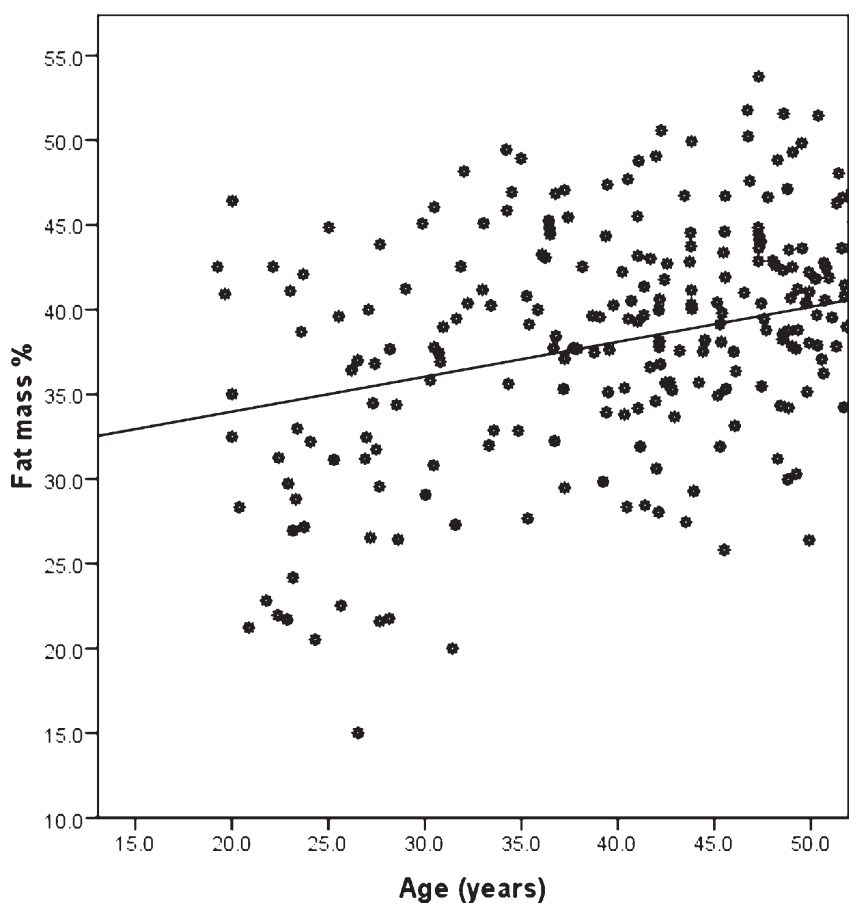

Figure 1: Correlation between age and FM \% in obese subjects.

\section{Discussion}

In the present study, body composition was measured using BIA on the basis of the water content in the body [13]. All measurements of body composition in our study were performed under strictly controlled conditions in accordance with the National Institutes of Health guidelines [14]. BIA is a common, simple, rapid, and noninvasive method to estimate total body water and FFM in healthy subjects as well as in obese subjects [15]. BIA has been cross validated in children adolescents against measurements of total body water by deuterium dilution [16] and total body potassium [17]. Similar validation studies are available for adults [18].

The present study showed age-related difference in body composition among obese females. In agreement with previous studies performed in obese adolescents, the higher BMR of our subjects can be explained mostly by their higher FFM as compared to older females. FFM, the metabolically active component of the body, explained $\sim 64 \%$ of the variability of BMR in our obese subjects, which suggests that other factors influence BMR [1921]. The present results agree also with other studies reported that fat mass was increased with age, but contradicts findings reported that there is little or no further gain in fat mass in older age 40-55 [17-20]. Generally, BMR depends on body composition as expressed by fat-free mass (FFM) and fat mass (FM) and on gender, age, physical activity, and nutritional status [26-28]. The lower BMR of older adults may be due in part to slowed organ metabolic rates and this may contribute to changes in FM and FFM. Moreover, other studies reported that the decline in BMR with advancing age could not be totally due to changes in body composition [29]. Severe obesity induces different agerelated adaptations of metabolism and body composition [30]. These differences might attribute to ethnic, nutrition and environmental differences. A significant effect of ethnicity was found for body composition components. There was an effect of ethnicity on FFM, Mexican elderly have different body compositions compared with AfricanAmerican and Caucasian adults of similar BMI and age [31].

The prevalence of obesity is very high among sedentary Egyptian women and the nutrition transition in Egypt has occurred in the context of abundant dietary energy availability [32]. The loss of FFM and muscle mass and increased fat mass with aging was documented in a number of studies using a variety of methods and it appears to occur even in relatively healthy persons. Solomon et al [33] reported that basal fat oxidation is reduced in obese elderly individuals as a function of age. Decreases in bone and muscle mass are characteristic features of normal human aging. In obese women, the quantification of body weight into its fat and FFM 
components is important in order to describe excesses or deficiencies FFM that have significant associations with the risk for functional independence and survival.

The present study confirms the limitation of using BMI as an indicator of fatness or leanness. Although the BMI was similar, older women had significantly higher $\mathrm{FM}$, and $\mathrm{FM} \%$ than younger women. Muscle makes up $50 \%$ of LM in young subjects, whereas half of the muscle mass has disappeared at age 75 because of reductions in both number and size of the myocytes [34]. In addition, the study shows that changes in fat mass, in terms in terms of percentage fat mass, might be related to changes in FFM with age. The greater decrease in FFM would suggest that the loss of skeletal muscle mass is greater than loss of non-skeletal muscle mass. Thus, the study suggests that the decline in BMR seems to be related to changes in FFM in older women.

In summary, the study defined age-related differences in body composition variables in the random sample of obese Egyptian females, aged 15-55 years.

\section{References}

1. Heitmann BL, Erikson H, Ellsinger BM, Mikkelsen $\mathrm{KL}$ \& Larsson B. Mortality associated with body fat, fat-free mass and body mass index among 60-year-old Swedish men-a 22year follow-up. The study of men born in 1913. Int J Obest Relat Metab Disord. 2000;24:33 - 37.

2. Sironi AM, Petz R, De Marchi D, Buzzigoli E, Ciociaro D, Positano V, Lombardi M, Ferrannini E, Gastaldelli A. Impact of increased visceral and cardiac fat on cardiometabolic risk and disease. Diabet Med. 2012;29:622-7.

3. Bemelmans RH, van der Graaf $Y$, Nathoe HM, Wassink AM, Vernooij JW, Spiering W, Visseren FL; SMART Study Group. Increased visceral adipose tissue is associated with increased resting heart rate in patients with manifest vascular disease. Obesity. $2012 ; 20: 834-41$

4. Speakman JR, Westerterp KR. Associations between energy demands, physical activity, and body composition in adult humans between 18 and 96 y of age. Am J Clin Nutr. 2010;92:826-34.

5. Steen B. Body composition and aging. Nutr Res. 1988;46(2): 45-51.

6. Dey DK, Bosaeus I. Comparison of bioelectrical impedance prediction equations for fat-free mass in a population-based sample of 75 y olds: the Nora study. Nutrition. 2003;19(10): 858-64.

7. Kyle UG, Genton L, Hans D, Karsegard L, Slosman DO, Pichard C. Age-related differences in fat-free mass, skeletal muscle, body cell mass and fat mass between 18 and 94 years. Eur J Clin Nutr. 2001;55:663-72.

8. Obisesan TO, Aliyu MH, Bond V, Adams RG, Akomolafe A, Rotimi CN. Ethnic and age-related fat free mass loss in older Americans: the Third National Health and Nutrition Examination Survey (NHANES III). BMC Public Health. 2005;5:41.

9. Fernández JR, Heo M, Heymsfield SB, Pierson RN Jr, PiSunyer FX, Wang ZM, et al. Is percentage body fat differentially related to body mass index in Hispanic Americans, African Americans, and European Americans? Am J Clin Nutr. 2003;77:71-5.

10. Harrison GG, Galal OM, Ibrahim N, Khorshid A, Stormer A, Leslie J, Saleh NT. Underreporting of food intake by dietary recall is not universal: a comparison of data from Egyptian and American women. J Nutr. 2000;130:2049-54

11. St-Onge MP, Gallagher D. Body composition changes with aging: the cause or the result of alterations in metabolic rate and macronutrient oxidation? Nutrition. 2010;26:152-5.

12. Hiernaux J, Tanner JM. Growth and physique: anthropometry. In: Weiner JS, Lourie JA, eds. Human biology, a guide to field methods. Philadelphia, FA Davis Company, 1969:2-42

13. Lukaski HC, Bolonchuk WW, Hall CB, Siders WA. Validation of tetrapolar bioelectrical impedance method to assess human body composition. J Appl Physiol. 1986;60:1327-1332.

14. NIHT. Bioelectrical impedance analysis in body composition measurement: National Institutes of Health Technology Assessment Conference Statement. Am J Clin Nutr. 1996;64(3 Suppl):S524-S532.

15. Houtkooper LB, Lohman TG, Going SB, Howell WH. Why bioelectrical impedance analysis should be used for estimating adiposity. Am J Clin Nutr. 1996;64(3 Suppl):S436-S448.

16. Wabitsch M, Braun U, Heinze E et al. Body composition in 5-18-y-old obese children and adolescents before and after weight reduction as assessed by deuterium dilution and bioelectrical impedance analysis. Am J Clin Nutr. 1996;64:16.

17. Schaefer F, Georgi M, Zieger A, Schärer K. Usefulness of bioelectric impedance and skinfold measurements in predicting fat-free mass derived from total body potassium in children. Pediatr Res. 1994;35:617-624.

18. Das SK, Roberts SB, Kehayias JJ et al. Body composition assessment in extreme obesity and after massive weight loss induced by gastric bypass surgery. Am J Physiol Endocrinol Metab. 2003;284:E1080-E1088

19. Chumlea WC, Guo SS, Kuczmarski RJ, et al. Body composition estimates from NHANES III bioelectrical impedance data. Int $\mathrm{J}$ Obes Relat Metab Disord. 2002;26:1596-609. 
20. Heitmann BL. Body fat in the adult Danish population aged 35-65 years:an epidemiological study. Int J Obes. 1991;15:535-45.

21. Kyle UG, Genton L, Hans D, Karsegard L, Slosman DO, Pichard C. Age-related differences in fat-free mass, skeletal muscle, body cell mass and fat mass between 18 and 94 years. Eur J Clin Nutr. 2001;55:663-72.

22. Doherty TJ. Invited review: Aging and sarcopenia. J Appl Physiol. 2003;95:1717-27.

23. Pichard C, Kyle UG, Bracco D, Slosman DO, Morabia A and Schutz Y. Reference values of fat-free and fat masses by bioelectrical impedance analysis in 3393 healthy subjects. Nutrition. 2000;16:245-254

24. Johnstone AM, Murison SD, Duncan JS, Rance KA, Speakman JR. Factors influencing variation in basal metabolic rate include fat-free mass, fat mass, age, and circulating thyroxine but not sex, circulating leptin, or triiodothyronine. Am J Clin Nutr. 2005;82:941-8.

25. Chumlea WC, Vellas B \& Guo SS. Malnutrition or healthy senescence. Proc Nutr Soc. 1998;57:593- 598.

26. Krems C, Lührmann PM, Strassburg A, Hartmann B, Neuhäuser-Berthold $M$. Lower resting metabolic rate in the elderly may not be entirely due to changes in body composition. Eur J Clin Nutr. 2005; 592:255-6.

27. Kyle UG, Genton L, Hans D, Karsegard L, Slosman DO,
Pichard C. Age-related differences in fat-free mass, skeletal muscle, body cell mass and fat mass between 18 and 94 years. Eur J Clin Nutr. 2001; 55:663-72.

28. Kyle UG, Genton L, Slosman DO, Pichard C. Fat-free and fat mass percentiles in 5225 healthy subjects aged 15 to 98 years. Nutrition. 2001;17:534-41.

29. Ito $\mathrm{H}$, Ohshima A, Ohto $\mathrm{N}$, et al. Relation between body composition and age in healthy Japanese subjects. Eur J Clin Nutr. 2001;55:462-70

30. Monda M, Messina G, Mangoni C, De Luca B. Resting energy expenditure and fat-free mass do not decline during aging in severely obese women. Clin Nutr. 2008;27:657-9.

31. Aleman Mateo H, Lee SY, Javed F, Thornton J, Heymsfield SB, Pierson RN, Pi Sunyer FX, Wang ZM, Wang J, Gallagher $D$. Elderly Mexicans have less muscle and greater total and truncal fat compared to African-Americans and Caucasians with the same BMI. J Nutr Health Aging. 2009;13:919-23.

32. Galal OM. The nutrition transition in Egypt: obesity, under nutrition and the food consumption context. Public Health Nutrition. 2002;5:141-8.

33. Solomon TP, Marchetti CM, Krishnan RK, Gonzalez F, Kirwan JP. Effects of aging on basal fat oxidation in obese humans. Metabolism. 2008;57:1141-7.

34. Rudman D. Growth hormone, body composition and aging. J Am Geri Soc. 1985;33:800-807. 